\title{
Information Ethics: An Environmental Approach to the Digital Divide
}

\author{
LUCIANO FLORIDI
}

Faculty of Philosophy, Department of Computer Science and Programme in Comparative Media Law and Policy Oxford University. Wolfson College, Oxford, OX2 6UD, UK. luciano.floridi@philosophy.oxford.ac.uk

\section{Introduction}

We call our society "the infor mation socie ty" because of the pivotal role played by informationintensives services (business and property services, commun ications, finance and insurance), public sector (education, public administration, health care) and intellectual, intangible assets (knowledge-based economy). As a social structure, the information society has been made possible by a cluster of information and communication techno logies (ICT). As a full expression of technē, the information society has already posed fundamental ethical problems, whose complexity and global dimensions are rapidly evolving. ${ }^{1}$ What is the best strategy to construct an information society that is ethically sound? This is the question I wish to discuss in this paper. Let me anticipate my conclusion. The task is to formulate an information ethics that can treat the world of data, information, knowledge ${ }^{2}$ and commu nication as a new environment, the infosphere. This information ethics must be able to address and solve the ethical challenges arising in the new environment on the basis of the fundamental principles of respect for information, its conservation and valorisation. It must be an ecological ethics for the information environment. In the rest of this paper, I shall defend and explain this view. ${ }^{3}$

\section{What is the Digital Divide?}

The digital divide(DD) is the source of many of the ethical problems emerging from the evolution of the information society. It is the combination of two gaps, one vertical and the other horizontal.

The vertical gap separates ours from past generations. In less than a century, we have moved from a state of submission to nature, through a state of power of potential total destruction, to the present state, in which we have the means and tools to engineer entire new realities, tailor them to our needs and invent the future. Humanity is increasingly responsible for the very existence of completely new environments. The technological power available is enormous. It is also growing relentlessly. In some scientific and technological contexts such as bio che mistry, biotechnolo gy and genetics, it is already so vast to have obliterated the distinction between the natural and the artificial. Moral responsibilities towards the world and future generations are therefore equally enormous. They go hand in hand with ontic 
power. Unfortun ately, technological power and moral responsibilities are not necessarily followed by ethical intelligence and wisdom. We are still like children, light-heartedly and dangerously toying with a marvellous universe. We may have almost demiurgic power over it, but we can rely only on our fallible good wills to guide us in our constructions.

The vertical gap signals the end of mod ernity. Post-modern critiques have unveiled the strategy of modernity as the techno-scientific colonization and domination of nature. Quoting Descartes, the goal of modernity was "[. . . to] use this knowledge [i.e. science and technology, my addition]-as the artisans use theirs-for all the purposes for which it is appropriate, and thus [to] make ourselves, a it were, the lords and masters of nature."4 The project of modernity was the full control and mastery over reality understood as the physical en vironmen t. It began with the semanticization of nature as its textualization, recall Galileo's view of physical reality as the "book of nature." It then developed through a society based on mass-produced goods, and ended with the semanticization of a textual culture as its deconstruction. The information age has been built on the modern project, but its essence is no longer just the shaping of the physical world. Rather, it is the creation and construction of alternative, non-natural environments that replace or underpin it. The mechanical mind handled nature and tried to control and mod ify it. The informational mind builds its own world and hence, in dealing with it, it really deals with its own artefacts. As a metaphorical space, the infosphere has grown through centuries, following the history of humanity, but as a real space "where" people meet, interact and spend an increasing amount of time (see Fig. 1) it is a new phenomenon, made possible by its digital imple mentation. I shall return to this distinction shortly.

The digital divide, of course, is also a new horizon tal gap within hu manity, betwe en inside rs and outsiders. The infosphere, often equated to its most prominent, digital region, namely cyberspace, is not a geographical, political, social, or linguistic space. It is the atopic space of mental life, from education to science, from cultural expressions to communication, from trade to recreation. Its borders cut across North and South, East and West, industrialised and developing countries, political systems and religious traditions, younger and older generations, even members of the same family. The scientist in Rio de Janeiro, the manager in New Delhi and the student in Paris, may all inhabit the infosphere and form a community of "netizens", citizens of the net. The architect in Miami, the lawyer in Tokyo and the medical doctor in Rome may well be complete outsiders. Obviously, economic and socio-cultural conditions matter. Indeed, the economic and sociocultural roots of the DD problem are so dramatic, evident and indisputable that nobody can underestimate them. ${ }^{5}$ Two billion people have no access to el ectricity, ${ }^{6}$ four billion people earn less than $\$ 1,500$ a year $^{7}$ and two billion people have never made a telephone call. ${ }^{8}$ To call them digitally "disadvantaged" or "underprivileged" is a pathetic and disrespectful understatem ent. On a global scale, it is fair to argue that basic alimentation, health, education and the acceptance of elementary human rights should be among humanity's foremost priorities. ${ }^{9}$ What needs to be stressed here, however, is that underestimating the importance of the DD, and hence letting it widen, means exacerbating these proble ms as well. In a global context, where systemic synergies and interactions are escalating, no significant problem comes in isolation; no crucial issue can be solved without considering the whole system of relations in which it is embedded. Thus, bridging the DD is probably part of the solution; $;^{10}$ leaving it unsolved is certainly part of the problem.

The DD does not merely mirror the divide between developed and developing countries, North and South of the world, rich and poor. Even where economic and socio-cultural factors are not a dramatic issue, the DD remains an acute problem. It is a problem within the US (see Fig. 2) and within Europe, for example. Consider the number of Internet hosts and mobile phones per 100 in habitan ts, two standard indicators for the growth of the information society: "the EU candidate countries are generally below the EU average. In 1999 none of them had reached the lowest EU rate for mobile phon es, but Eston ia, Malta, Hun gary, the Czech Republic and Slovenia had more Internet hosts than the least equipped EU coun tries, Greece and Italy."11

It seems more accurate to say that the DD reshapes the social map because it occurs between individuals rather than countries or whole societies, between the computer literate and the computer illiterate (e-analphabetism), between the information rich and the information poor, whatever their nationality and neighborhood. The DD abolishes space and time constraints but creates new technological barriers betwee $n$ insiders and outsiders. According to a report published in 2000 by the OECD (www.oecd.org), the ratio of Web hosts to population in North America, compared to Africa, had doubled since 1997. Currently, only $7 \%$ of the world's 
population has access to ICT. ${ }^{12}$ They are the insiders, who can play some role in the life of the new digital environment and shape its future. The remaining $93 \%$ of outsiders, some of whom live in G- 8 countries, are not merely marginalized, they actually live under the shadow of a new digital reality, which allows them no interaction or access, but which can in fluence their lives pro foundly.

\section{Coping with the Digital Divide}

The DD disempowers, discriminates, and generates dependency. It can engender new forms of colonialism and apartheid that must be prevented, opposed and ultimately eradicated. How can we cope with the new ethical challen ges? Since the DD is a problem affecting individuals rather than preestablished whole societies, solutions can be more effective if they are grassroots-oriented and bottomup. Unfortunately, old solutions to past ethical problems cannot be me rely exported and mechanically re-applied to the infosphere. Missing this point would mean having failed to learn any lesson from past experience. Technologies are not only tools, but also vehicles of affordances, values and interpretations of the surrounding reality, like hermeneutic devices. Any significant technology is always ethically charged. Natu rally, other technolo gical innovations (the printing or industrial revolutions, for example) had their own pressing ethical consequences. Some of them are still with us, think of universalliteracy, freedom of speech, sustainable development, or pollution. However, the ethical impact of past technologies took place within a context in which nature played the queen and we were her workers. Ethical problems developed on a much longer time scale, they did not have the immediately global and pervasive nature we associate with ICT nowadays and were not embedded in a context where the virtual and the digital have started to become sometimes more significant and real than the physical. All this guaranteed some con tinuity in the ethical discourse. Ethical issues could still be interpreted as mere upgraded techno-versions of classic old problems. The computer revolution has further increased the magnitude of the ethical impact of technological innovations and finally reached a critical threshold of change. It has brought about the end of modernity and the transformation of its project, shifting the focus from control to construction. ICT has put humanity in charge of the implementation of the hyperreality inhabited by the citizens of the information society. We are now more the en gineers than just the regulators of our environment. This is the crucial historical difference compared to any previous technological revolution. The problem is that our ethical development has been much slower than our technological growth. We can do so much more than we can understand. Upgrading our moral sensibility is a slow process.

The infosphere is a transversal environment that is essentially intangible and imm aterial but not, for this reason, any less real or vital. The ethical problems it generates are best understood as environmental problems. They include e ducation as capacity-building training; preservation, dissemination, quality control, reliability, free flow and security of information; enlargement of universal access; technical support for the creation of new digital "spaces"; the sharing and exchanging of public contents; respect for diversity, pluralism, ow nership and privacy; ethical use of ICT; integration of traditional and new $\mathrm{ICT},{ }^{13}$ digital vandalism. To alleviate these and similar problems we need a robust ecological approach, which can provide a coherent guidance for the equitable development of this new space for intellectual life. In short, we need an information eth ics.

\section{Informa tion Ethics and the E cology of the Infosphere}

Information Ethics is the new ecological ethics for the information environment. It argues that the digital divide $\mathrm{c}$ an be bridged. What we need to do is to fight any kind of destruction, corruption, pollution, depletion (marked reduction in quantity, content, quality, or value) or unjustified closure of the infosphere, what shall be referred to here as information entropy. The ethical use of ICT and the sustainable development of an equitable information society need a safe and public infosphere for all, where communication and collaboration can flourish, coherently with the application of civil rights, legal requirements and the fundamental freedoms in the media. An ecological model for thinking about bound ary issues in the infosphere is important to foster the development of ethical rules and legislation about accessing, sharing, and manipulating information. Data security and protection and information supply, for example, are technical problems comparable to the problem of keeping toxic waste out of the water supply. The analogy is anything but farfetched. The city of Houston (T exas) recently decided to pro vide its 1.8 million citizens with free e-mail service and access to word processing software. Commenting on this 
decision, the city's chief information officer, Denny Piper, argued that these are services with which citizens should be provided by city government, "like water and public works". As in the case of those services, we need to d evelop an ecological perspective about information resources.

Sustainable development means that our interest in the sound construction of the infosphere must be associated with an equally important, ethical concern for the way in which the latter affects and interacts with the physical environ ment, the biosphere and human life in general, both positively (e.g. telework as a solution for traffic and fuel pollution) and negatively (e.g. rising energy consumption, ICTgenerated waste, compu ter-related forms of illness). ${ }^{14}$

Bridging the DD means developing an informational ecosystem management that can implement fourbasic norms of a universal information ethics:

1. information entropy ought not to be caused in the infosphere

2. information entropy ought to be prevented in the infosphere

3. information entropy ought to be removed from the infosphere

4. information ought to be promoted by extending, improving, enriching and opening the infosphere, that is by ensuring information quantity, quality, variety, security, ownership, privacy, pluralism and access.

These universal principles represent a development of the ethical discourse in Western culture, which has gradually abandoned its anthropocentric perspective. They re-evaluate an ethics of respect for both the physical and the immaterial world. ${ }^{15}$ An information ethics for the information society needs to take into serious conside ration the value of what is immaterial and intangible. This is the best way to foster care and respect for the infosphere. Reality, both natural and immaterial, physical and digital, is not merely available for domination, control, and exploitation. Reality should also be an object of respect in its autonomous existence. This is what we can learn from an environmental approach. However, history has its ironic twists, and precisely those high-technology societies, which have brought about the information revolution, seem to be the least able to cope with its ethical impact. Pre- or non-indu strial cultures, which have been able to maintain a n on-material istic and nonconsumistic approach to the world, are still spiritual enough to perceive in both physical and immaterial realities something intrinsically worthy of respect, simply as forms of existence. They may not be environm entally sensitive, but they can be important sources to develop an ecological approach that will make the infosph ere a more civilized space for all. The environm ental ethics of the infosphere mustbe built by considering also the needs and input of its "outsiders".

\section{Conclusion}

In 2003, at the World Summit on the Information Society and at the $21^{\text {st }}$ World Congress of Philosophy, one of the tasks of the international commun ity will be to build global consensus around a core of ethical values and principles for the information society. International cooperation and consultations are already in progress. ${ }^{16}$ There is a profound and widespread need for analysis and ethical guidance. ${ }^{17}$ Fostering the formulation of universally recognized principles and common ethical standards related to the use of ICT and based on an environmental information ethics will be a major contribution to the construction of a better world. It is not a matter of imposing legislative measures, strict regulations or empowering some controlling organization. The goals are to extend the ethical concern from the biosphere to the infosphere, to sensitize humanity to the new ethical needs of intangible, intellectual environments, and to indicate how the DD can be bridged. Our challenge is to collaborate to develop a coherent and robust environmental information ethics for the future of humanity. Building an equitable information society for all is a historical opp ortunity we cannot afford to miss. ${ }^{18}$ 
Fig. 1

\begin{tabular}{|lrrrr}
\cline { 1 - 2 } Internet Usage Statistics & \multicolumn{1}{c}{ June 1999 } & May 2000 & \multicolumn{1}{c}{ April 2001 } \\
Sessions per month & 17 & 18 & 19 \\
Unique sites visited & 12 & 10 & 10 \\
Time spent per site & $37: 41$ & $56: 23$ & $55: 40$ \\
Time spent per month & 0.31560185185 & 0.37875 & 0.39806712963 \\
Time spent per session & $26: 44$ & $29: 50$ & $30: 35$ \\
Duration of page viewed & 0.0555555556 & 0.0347222222 & 0.0361111111 \\
Active Internet Universe & 63394081 & 82682454 & 103056022 \\
Estimated Internet Universe & 105371050 & 134209269 & 167479153
\end{tabular}

Source:

Nielson//NetRatings, http://209.249.142.16/nnpm/owa/N Rpublicrepo rts.usagemonthly

According to a recent study from the UCLA Center For Communicati on Policy (http://www.ccp.ucla .edu/), in the US, more web users are spending increasing time on the Internet primarily to communicate (e-mail), browse, buy and seek entertainment, and to read news, in order of popularity. $72.3 \%$ of Americans went online in 2001 , up from $66.9 \%$ in the center's 2000 survey. Time spent online was also up, from 9.4 hours per week in 2000 to 9.8 hours per week (source: Surveying the Digital Future, http://www.ccp.ucla.edu/pdf/UCLA-Internet-Report-2001.pdf).

Fig. 2

\begin{tabular}{|l|l|l|}
\hline \multicolumn{3}{|c|}{ The Have's and the HaveNot's } \\
\hline Who & $\begin{array}{l}\text { Have Internet } \\
\text { Access }\end{array}$ & $\begin{array}{l}\text { Do Not Have } \\
\text { Access }\end{array}$ \\
\hline Men & $51 \%$ & $49 \%$ \\
\hline Women & $46 \%$ & $54 \%$ \\
\hline White & $50 \%$ & $50 \%$ \\
\hline Black & $36 \%$ & $64 \%$ \\
\hline Hispanic & $44 \% \%$ & $56 \%$ \\
\hline Age & & \\
\hline $18-24$ & $65 \%$ & $35 \%$ \\
\hline $24-29$ & $65 \%$ & $35 \%$ \\
\hline $30-39$ & $61 \%$ & $39 \%$ \\
\hline $40-49$ & $55 \%$ & $45 \%$ \\
\hline $50-59$ & $44 \%$ & $56 \%$ \\
\hline $60+$ & $17 \%$ & $83 \%$ \\
\hline Household Income & & \\
\hline Less than $\$ 30,000$ & $31 \%$ & $69 \%$ \\
\hline$\$ 30,000-\$ 50,000$ & $52 \%$ & $48 \%$ \\
\hline \$50,000-\$75,000 & $67 \%$ & $33 \%$ \\
\hline \$75,000 and above & $78 \%$ & $22 \%$ \\
\hline Education & & \\
\hline Did not graduate from Highl $7 \%$ & $83 \%$ \\
\hline High School Graduate & $34 \%$ & $66 \%$ \\
\hline Some College & $63 \%$ & $37 \%$ \\
\hline College+ & $75 \%$ & $23 \%$ \\
\hline Source: Peer Internet Project average behavior March \& August 2000 \\
\hline
\end{tabular}




\section{Notes}

1. See the Okinawa Charter on Global Information Society, (http://www.g8kyushuokinawa.go.jp/e/documents/it1.html), especially paragraph 18, which called for the formation of the Digital Opportunity Task Force (DOT Force), a Digital Divide initiative of the Group of Eight (G-8); the documents provided by the DOT Force at http://www.dotforce.org, especially DOT Force Draft Report Version 1.x, $\mathrm{http} / /$ www.dotforce.org/reports/dotforce-draft-report-v1.doc; the documents provided by the Organisation for Econom ic Co-ope ration and D evelopm ent (OEC D, http://www.o ecd.org/), espe cially Understanding the Digital Divide, http://www.oecd.org/dsti/sti/prod/Digital_divide.pdf; and the UNESCO Observatory on the Information Society, http $\% /$ www.unesco.org/webworld/observatory/index.shtml

2. For th is distinction, se L. Floridi, Philosophy and Computing (New York and Lond on: Routle dge, 1999).

3. For an in itial deve lopment of Inform ation E thics an $\mathrm{d}$ a more technical treatment of some of the themes discussed in this paper see the following papers, available from http://www.wolfson.ox.ac.uk/ floridi/papers.htm: "Does Information have a Mo ral Worth in Itself?"; "Computer Ethics: Map ping the Foundatio nalist Debate"; "Artificial Evil and the Foun dation of Com puter E thics" (w ith J. W. S anders), Ethics and Information Technology 2001 (3 .1), pp. 55-66; "Information Ethics: On the Theoretical Foundations of Computer Ethics", Ethics and Information Technology 1999 (1.1), pp. 37 -56; "Entropy as Evil in Information Ethics" (with J. W . Sanders), Etica \& Politica, special issue on Computer Ethics, I.2 (1999). Oxford Un ivers ity, Computing Laboratory, Programming Research Group Technical Report TR-5-0 0; “The Internet: Which Future for Organised Knowledge-Frankenstein or Pygmalion?”, International Journal of Human-Computer Studies 43 (1995), pp . 261-2 74.

4. Descartes, Discourse on the Method, Part VI, C. Adam and P. Tannery (eds.), Oeuvres de Descartes, rev. ed., 12 vols. (Paris: Vrin-CNRS, 1964-76), vol VI, p. 62; English trans. in J. Cottingham, R. Stoothoffand D. Murdoch (eds.), The Philosophical Writings of Descartes, 2 vols. (Cambridge: Camb ridge Univ ersity Press, 1984), vol. I, pp. 142-3.

5. Valuable statistical data are provided by the OECD document Understanding the Digital Divide, cit. above, http://www.oecd.org/dsti/sti/prod/Digital_divide.pdf

6. Time magazine special report on "Our Wired World", June 4, 2001.

7. Businessesweek, December 18 2000, special issue dedicated to the digital divide http ://www.wri.org/bu sine ss/b wfinal.pdf

8. Source: Global Bridges, Digital Opportunities: Draft Report of the DOT Force, http://www.dotforce.org/reports/dotforce-draft-report-v1.doc, page 9.

9. Over-optimistic and utterly unjustified "visions" are not rare, see for example A. Hammond "Bottom-Up, Digitally-Enabled Development: A vision”, iMP, February 2001 , http //www.cisp.org/imp/february_2001/02_01hammond.htm; and "Digitally Em powere d Development",Foreign Affairs, March-April 2001, http://www.digitaldividend.org/pdf/0201ar04.pdf. Bill Gates' assessment of the difficulties encountered in bridging the digital divide are far more realistic, see "Bill Gates Turns Skeptical On Digital Solution's Scope", New York Times, November 3, 2000.

10 The possibility is analysed in Julian a Gruenwald, "Seeking Answ ers to the G lobal 'D igital Divid e'", Interactive Week, January 14, 2001, http://ww w.zdn et.com/intwe ek/storie s/news/0,4164,267 4126,00.htm 1.

11. Sources: Eurostat Yearbook 2000, http://europa.eu.int/comm/eurostat/Public/datashop/printproduct $/$ EN?catalogue $=$ Eurostat\&product $=1-12062001-E N-A P-E N \&$ mode $=$ download; Eurostat Information Society Statistics, http://europa.eu.int/comm/eurostat/Public/datashop/printproduct/EN?catalogue $=$ Eurostat $\&$ product $=$ KS-NP-01-023-__-I-EN\& mode $=$ download 
12. Source: Time magazine special report on "Our Wired World", June 4, 2001.

13. For an instructive approach to integration of new and traditionalICT see the final report on UNESCO Seminar (Kothmale, Sri Lanka, 22-27 January, 2001), prepared by I. Pringle, $\mathrm{http}: / /$ ww w.un esco .org/web world/ko thm ale/s eminar_repo rt.pd f

14. See the final report on UNESCO Se minar on Integration of New and Traditional ICT, cited above.

15. For the development of an ethic al attitude towards information objects and the infosphere see L. Floridi "On the Intrinsic Value of Information Objects and the Infosphere" (forthcoming), preprint available at http $/ /$ www.wolfson.ox.ac.uk/floridi/papers.htm

16. For an overview of some literature and results see The Public Voice and the Digital Divide: A Report to the DOT Force, http $/ /$ www.thepublicvoice.org/dotforce/report_0301.html Some of the information contained in this paper are from this useful report. Note that the report do es not mention UNESCO activities in this context.

17. The international community may naturally look at UNESCO as one of the principal sou rces for conce ptual and ethical guidance. UNESCO Medium-Term Strategy strongly emphasizes that the Organization needs to develop an efficient and effective strategy to deal with the new ethical challenges arising in the development of the information society, see Medium-T erm Strategy (2002-2007), Draft 31C/4 "Contributing to peace and hum an development in an era of globalisation through education, the sciences, culture and communication", http ://un esdo c.un esco .org/imag es/0 012/00 1223/1 223 79e.pdf

18. This is a revised version of an invited address given at the UNESC O Executive Bo ard 161st Session Thematic debate "The New Information and Communication Technologies for the Development of Education", UNESCO, Paris, Thursd ay, 31 May 2001 . I am very grateful to all participants to the debate session for their comments, and to Vito di Bari, Michiel Brumsen, Charles Ess, Massimiliano Lattanzi, Kia Nobre, Mario Panaro, Jeff Sanders and Gabriele Sardo for the ir feedback on previous drafts. I am also grateful to Philosophy in the Contemporary World's anonymous referee for several sugg estions on how to im prove the paper. 